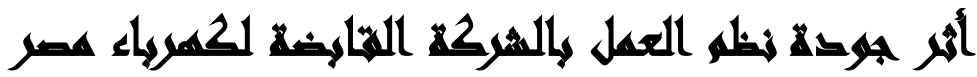

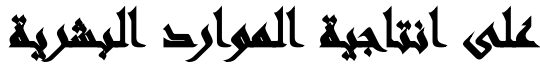

[IV]

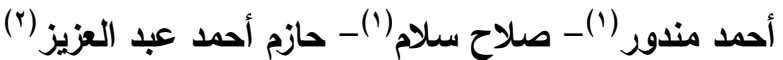

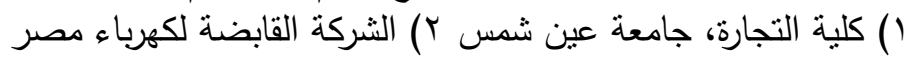

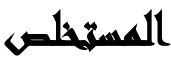

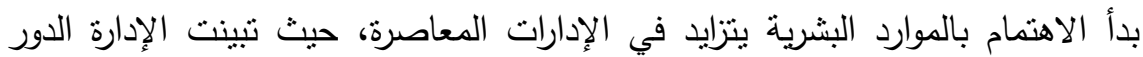

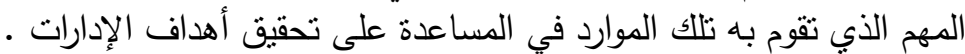

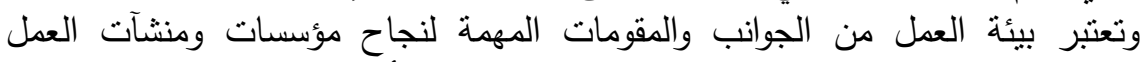

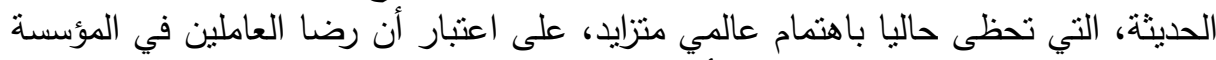

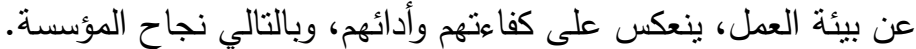

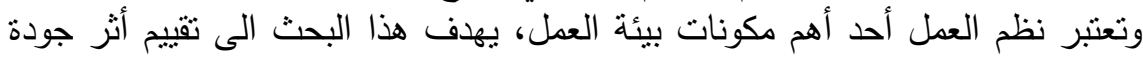

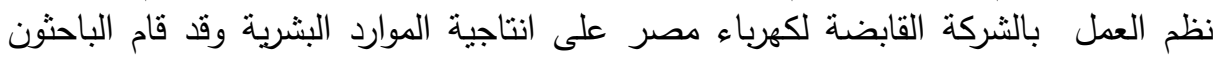

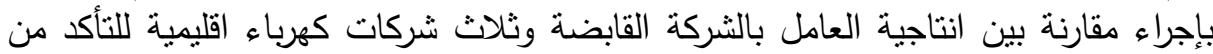

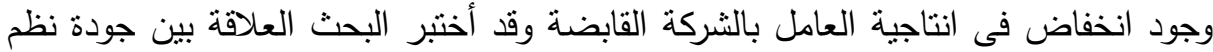

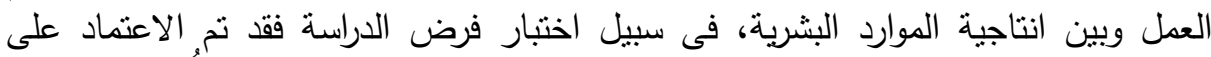

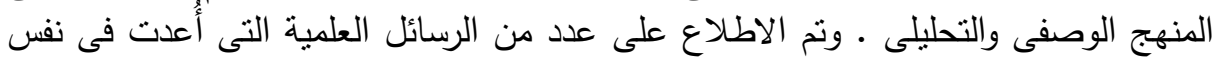

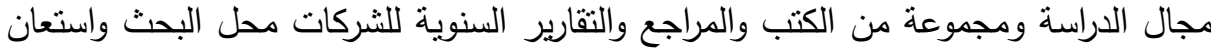

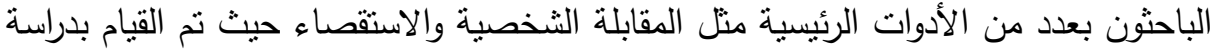

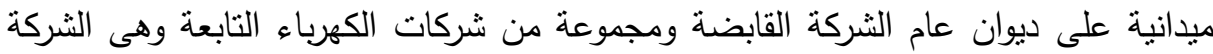

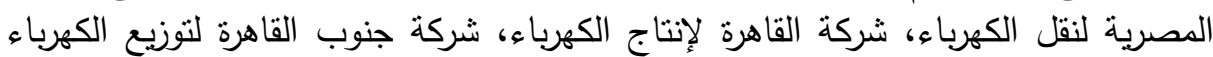

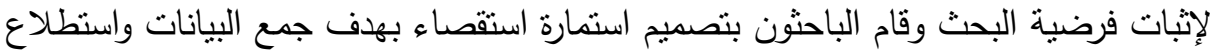

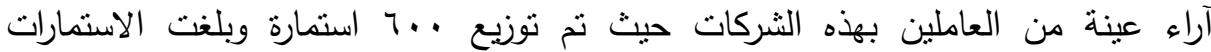

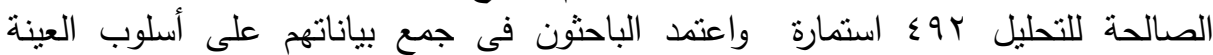

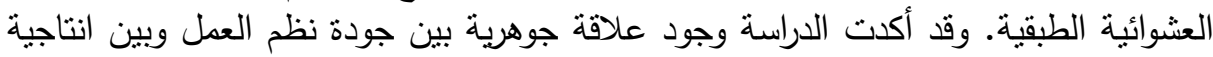

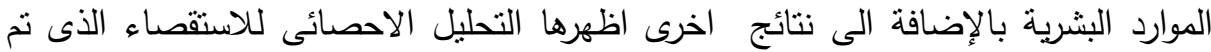

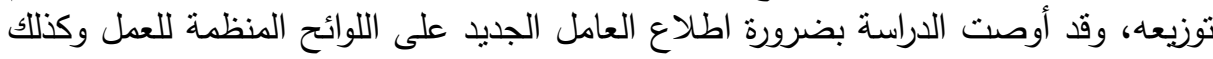

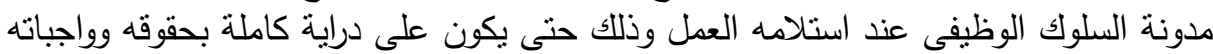

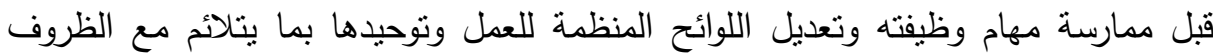

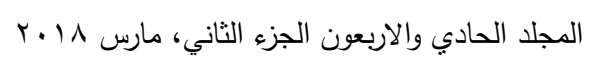


الحالية التى تمر بها الثركة، وكذلك مراجعة الاجراءات الحالية بالثركة وتبسيطها لتقليل

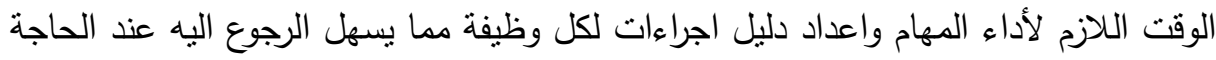

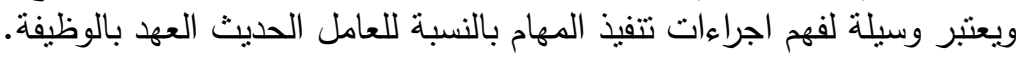

\section{Iasion}

بدأ الاهتمام بالموارد البشرية يتزايد في الإدارات المعاصرة، حيث تبينت الإدارة الدور المهم الذي تقوم به تللك الموارد في المساعدة على تحقيق أهداف الإدارات. إن الإنسان يزيد عطاءه وترتفع كفاءته إذا عمل في مجموعة (فريق) من الزملاء

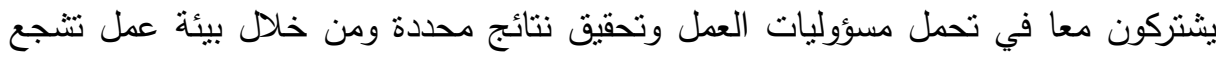

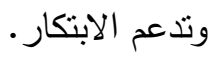

فبيئة العمل من الجوانب والمقومات المهمة لنجاح مؤسسات ومنشآت العمل الحديثة، التي تحظى حاليا باهتمام عالمي متزايد، على اعتبار أن رضا العاملين في المؤسسة عن بيئة

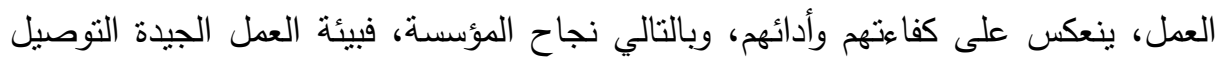
تحفز ابداع العاملين، وسوء ظروف العمل زساهم فى خفض انتاجية العاملين. ( A kinyele Samuel Taiwes, 2010 )

وتعد بيئة العمل الداخلية واحدة من أهم التحديات الرئيسة التي يجب على كل مؤسسة

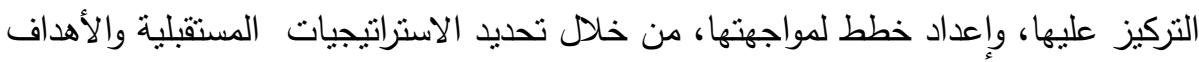
الكلية للمؤسسات على اختلاف نشاطاتها، أو نطاق عملها، الأمر الذي ينعكس إيجابياً على

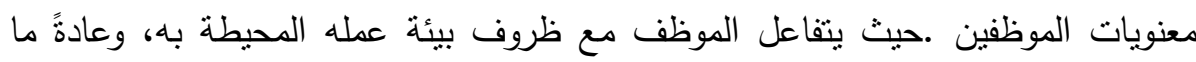

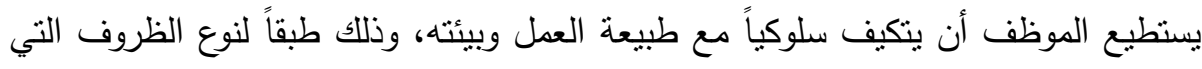
تواجهه أثناء تواجده في العمل (سعيد القحطاني، 2012).

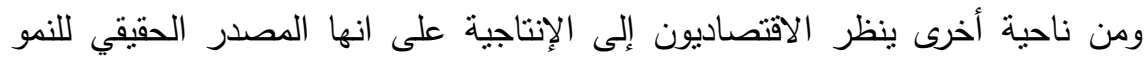
الاقتصادي والرفاهية الاجتماعية وتحسين مستوى المعيشة في أب بلد، مهما كان نوع النشاط الإنيه

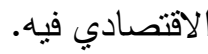


إن معدلات نمو الإنتاجية وتحليل عناصرها تعطي نظرة فاحصة للنشاط الاقتصادي، وتكثف نواحي الضعف والقوة في هذا النشاط. لهذا تتسابق الدول للمحافظة على استمرارية معدلات نمو متزايدة في الإنتاجية بإدخال التحسينات المستمرة في الجوانب التكنولوجية والإدارية والبشرية، وتمكنت الدول المتقدمة عن هذه الطريق من تحقيق تقدم صناعي كبير

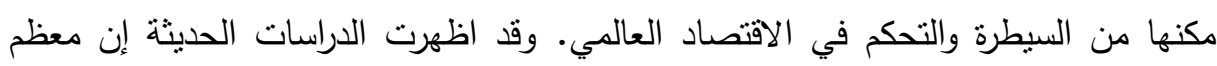
مشاكل انتاجية العاملين تقع داخل بيئة العمل (Nakpodia, E. D, 2011 )

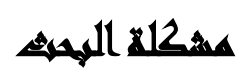

نبعت مشكلة الدراسة نتيجة تنخيص واقع بيئة العمل بالثركة القابضة لكهرباء مصر

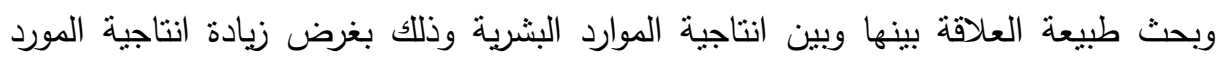
البشرى بالثركة. وللتأكد من وجود مشكلة تتعلق بانخفاض انتاجية العمل بالثركة فقد قام الباحث بمقارنة إنتاجية العامل بالثركة مع انتاجية العامل في ثلاث شركات كهرباء مماتلة في باتئي كل من المملكة العربية السعودية، وسلطنة عُمان، ودولة جنوب أفريقيا وذلك خلال فترة زمنية

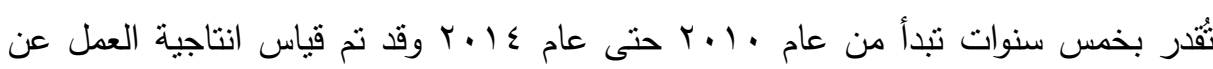
طريق استخدام المعادلة التالية: إنتاجية العامل = كمية الطاقة المباعة / عدد العاملين وقد روعى فى اختبار شركات الكهرباء محل المقارنة النواحى التالية: 1- أن تكون شركات مساهمة وأسهوها مدلوكة للدولة ( أى توافر المناخ الاحتكارى للشركة )

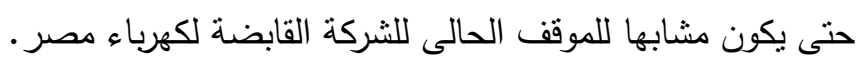

r- ان يضم نشاطها الانتاج والنقل والتوزيع حتى تكون انتاجية العامل معبرة عن كافة العمليات التى تتم منذ بدء الانتاج وحتى وصول الطاقة الكهبائية الى المستهلك الأخير . r- أن تتشارك دول هذه الثركات مع مصر فى الظروف العامة اقليميا حتى تكون المقارنة

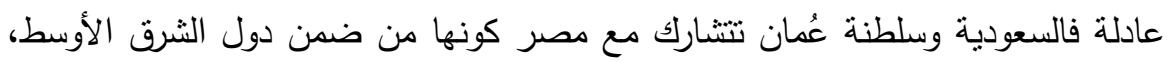
وجنوب أفريقيا ومصر كونها ضمن دول الاتحاد الافريقى.

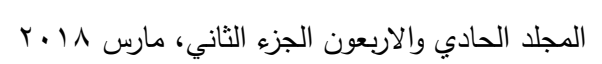


أظهرت المقارنة ان متوسط انتاجية العامل فى الثركة القابضة لكهرباء مصر V V, •

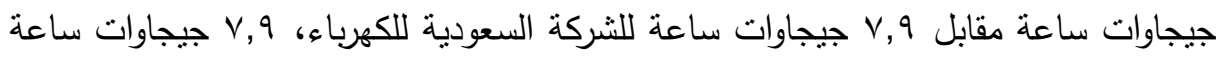

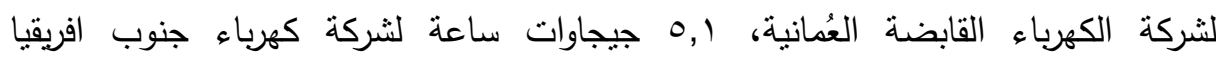
(الجيجا وات ساعة هى وحدة قياس الطاقة الكهريائية وهى تساوى ... (ESKOM)

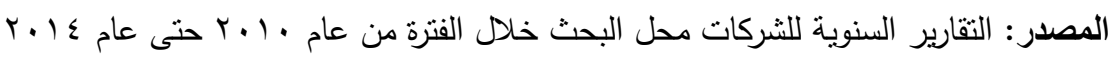

\section{سوالال الهيهـ}

ما مدى تأثير جودة نظم العمل فى الثركة القابضة لكهرباء مصر على إنتاجية الموارد البشرية؟

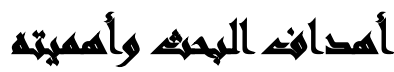

يحاول الباحثون من خلال هذا البحث ان يختبروا العلاقة بين جودة نظم العمل فى الثركة القابضة لكهرباء مصر وبين إنتاجية مواردها البشرية وذلك بغرض تقيئم هذه العلاقة وتقديم مقترح لتحسين إنتاجية الموارد البشرية بهاء ويمكن تصنيف أهية الدراسة من خلال الأتى : من الناحية العلمية: تتمثل أهمية البحث فى نتاوله العلاقة بين جودة نظم العمل وإنتاجية المورد البشرى وبما يمثل إضافة من إثراء معرفى يمكن ان يضاف الى المكتبة الجامعية فى جي هذا المجال. من التاحية العملية: تتمثل أهمية البحث فى أنه يتتاول سبل تحسين انتاجية الموارد البشرية بالثركة القابضة لكهرباء مصر وتقدم نتائج وتوصيات يمكن لقيادات الثركة الاستفادة منها مما قد يكون له أثز إيجابى على انتاجية العاملين بها وبالتالى لها أثنار اجتماعية ايجابية

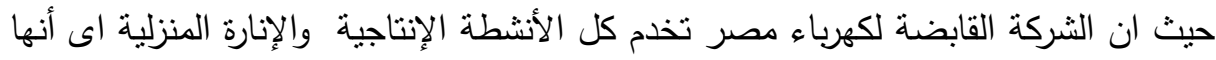

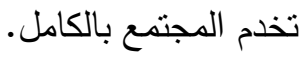




\section{منهجية الترواسلة}

فى سبيل اختبار فروض الدراسة تم الاعتماد على المنهج الوصفى والتحليلى والذى ينطلب تحليلا كاملا لكافة البيانات التى تم جمعها وتحليلها بأكبر درجة ممكنة من الدقة.

\section{مبوض القواسم}

الحدود المكانية: الثركة موضع الدراسة هى الثركة القابضة لكهرباء مصر • الحدود الزمانية: الفترة التى تغطيها الدراسة سلسة زمنية قدرها ه سنوات اعتبارا من العام

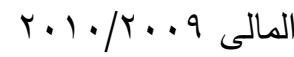
أدوات ومصادر الاراسة: استعان الباحثون بعدد من الأدوات الرئيسية والمصادر المساعدة ذات العلاقة بموضوع البحث وهى على النحو التالى:

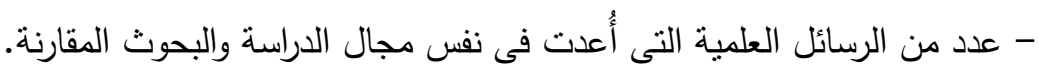
- مجموعة من الكتب والمراجع والإصدارات العلمية التخصصية. - التقارير السنوية للشركات محل البحث.

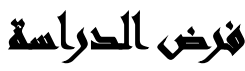

استتادا الى مشكلة الدراسة فقد تم صياغة الفرض الرئيسي التالي: هناك علاقة جوهرية ذات

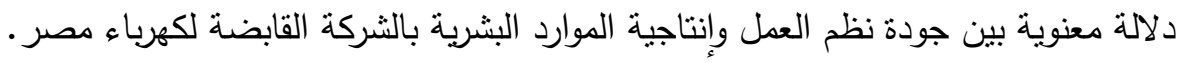

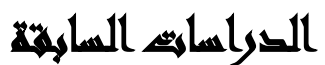

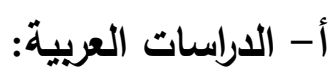

1- دراسة بوقال نسيم عام r Y ب بعنوان " أثر بيئة العمل الاخلية للمنظمة على الرضا الوظيفى للعاملين " تهدف الدراسة للتعرض لأهم جوانب العلاقة بين بيئة العمل الداخلية والرضا الوظيفى للعاملين ومن ثم إسقاط الدراسة النظرية على ديوان الترقية والتسبير العقاري لهني لولاية قسطنطينة بالجزائر كجانب تطبيقي وقد تبين كنتيجة رئيسية للاراسة أن لبيئة العمل

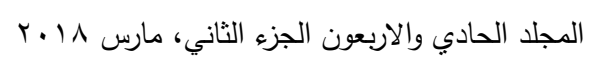


الداخلية أثرا مهما على الرضا الوظيفي للعاملين سواء كان ذلك بشكل إيجابي من خلال أثر

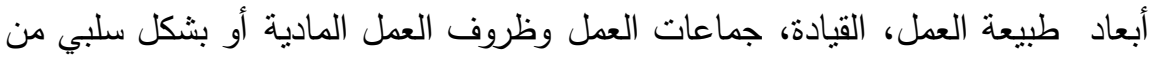

$$
\text { خلال بُعدى الحوافز والأجور والاتصال. }
$$

وقد أوصت الدراسة بالتأكيد على ضرورة وجود قيادات إدارية واعية، تمتلك المهارة والخبرة اللازمة للتحكم بالمنظمة وتسييرها بأفضل السبل، والعمل على تقريب المسافة بين الإدارة

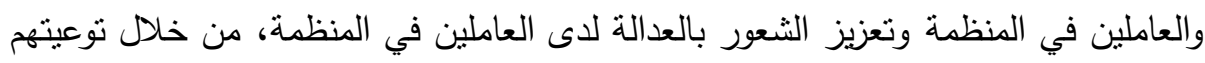
بالأسس التي ينت من خلالها منح المكافآت والحوافز والترقية...إلخ، مع وضع معائ معايير موضوعية

$$
\text { لتقييم الأداء يتم الالتزام بها. }
$$

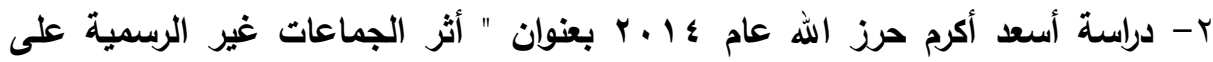
الإنتاجية: دراسة حالة على الموظفين في شركة الاتصالات الخلوية الفلسطينية - جوال

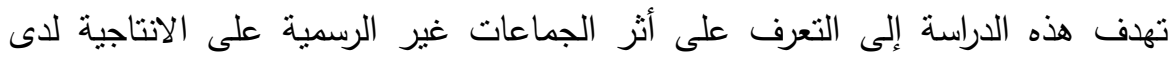
العاملين فى شركة جوال وقد تم إتباع المنهج الوصفى التحليلى فى هذه الدراسة، ولتحقيق

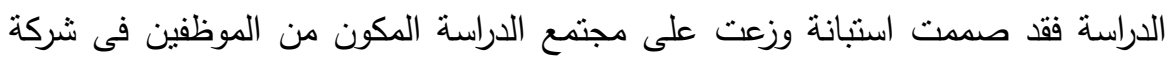

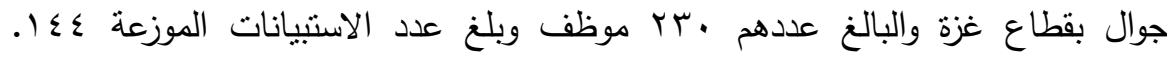

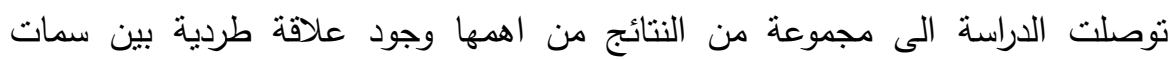

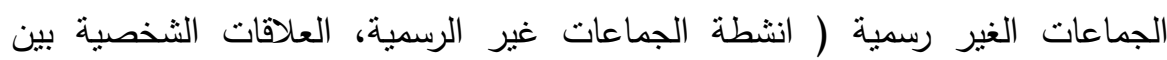
الجماعات غير الرسمية، الالتزام الوظيفى للجماعات غير الرسمية، الرضا الوظيفى الوشئ

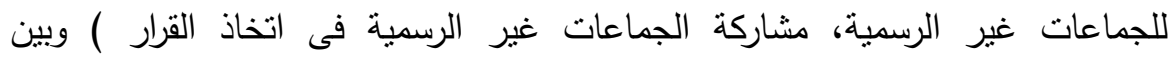
الانتاجية. وأوصت الدراسة بمجموعة من التوصيات اهمها دعم الاتصالات بين الجماعات غير الرسمية، وتوفير مقومات الالتزام الوظيفى للجماعات غير الرسمية وذللك من خلال

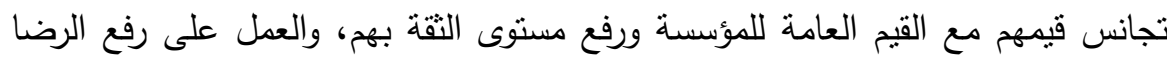
الوظيفى للجماعات غير الرسمية من خلال تحسين العلاقة بين الرؤساء والمرؤوسين

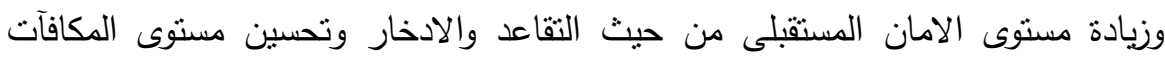
والترقيات. 
r- دراسة سهام بن رحمون ؛ 1 بـ بعنوان " بيئة العمل الاخلية وأثرها على الاداء الوظيفى " تهذف الدراسة إلى معرفة مدى استيفاء بيئة العمل الداخلية لعناصرها المادية والإدارية المكونة لها، ومدى رضا الاداريين عن بيئة عملهم الداخلية فى جامعة باتتة بالجزائر • وقد أسفرت النتائج عن استيفاء بيئة العمل الداخلية لعناصرها المادية والادادية الإية

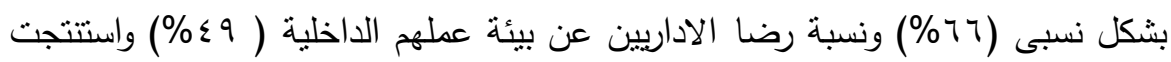

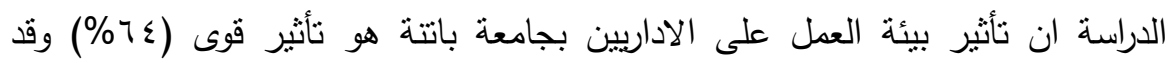

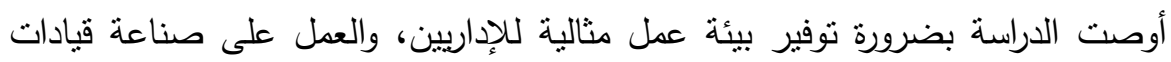
ادارية ناجحة تتماشى مع متطلبات العصر والعمل على توظيف الاداريين فى مناصبهم وفق تخصصهم العلمى والعمل على توفير نظام اتصال ادارى فعال.

$$
\text { ب:- الدراسات الأجنبية }
$$

1- Markey, et al. (2012): The Impact of The Quality of The Work Environment on Employees' Intention to Quit"

هدفت الدراسة إلى التحقيق في مفهوم جودة بيئة العمل بأبعاده (ملائمة بيئة العمل، توافر

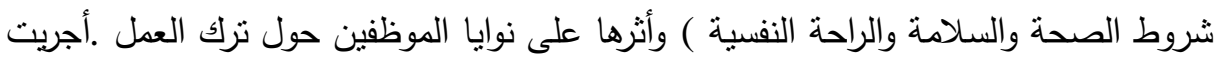

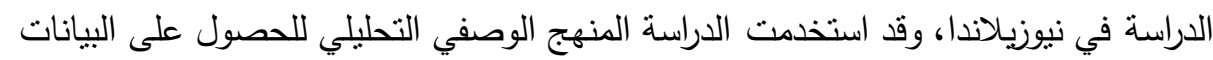

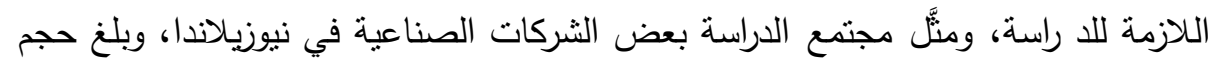

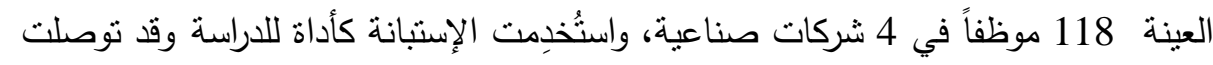

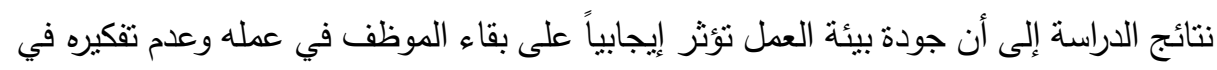

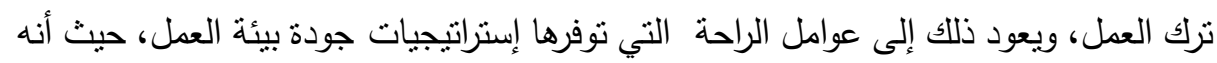
كلما كانت بيئة العمل ملائمة ومريحة وتتوفر فيها جميع شروط الصحة والسلامة والراحة

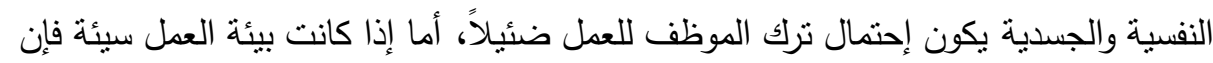

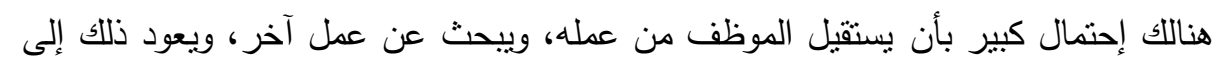

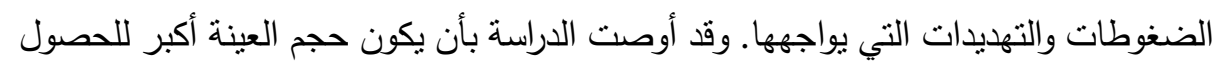

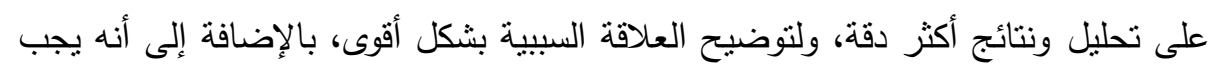
تسليط الضوء على توسيع نطاق جودة بيئة العمل ليشمل جميع الشركات في نيوزيلاندا.

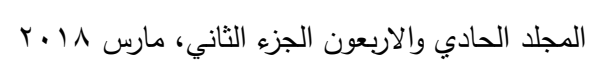


2- Leblebici (2012) :" Impact of Workplace Quality on Employee's Productivity: Case Study of a Bank in Turkey

هدفت الدراسة إلى إستكثاف العلاقة بين جودة مكان العمل بأبعادها مكونات البيئة المادية منل التهوية، التدفئة، الإضاءة الطبيعية، الإضاءة، والديكور ، ومكونات البيئة السلوكية مثل: التفاعل الاجتماعي، البيئة المادية الإبداعية، والجو العام ) وبين انتاجية الموظفين .

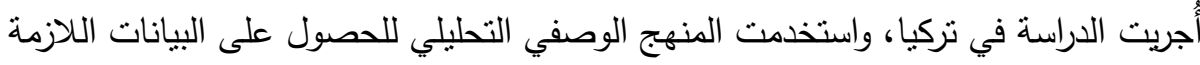
للاراسة، ومنَّل مجتمع الدراسة بنك تجاري في تركيا، وبلغ حجم العينة 50 موظفاً يعملون في لراسي

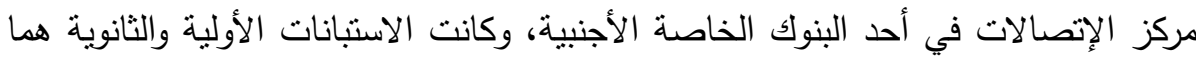

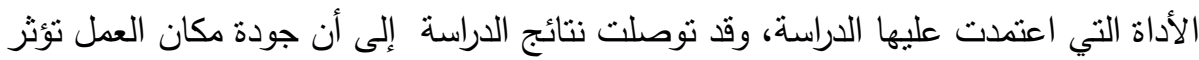
بشكل كبير في تحسين إنتاجية الموظفين، حيث أن الإهنمام بمكان العمل بعد من أهم العوامل

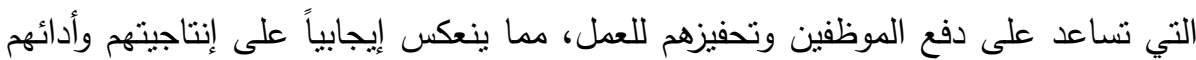
الوظيفي، ويقلل من الأخطاء ويزيد من مستويات الإبداع والإبتكار والتعاون بين الموظفين .

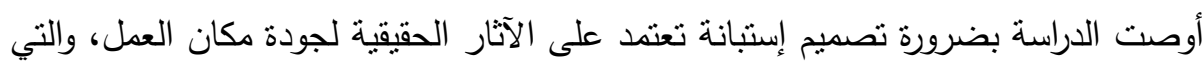
تتعكس بدورها على إنتاجية الموظفين، وليس بناءً على تصورات الموظفين حول جودة مكان

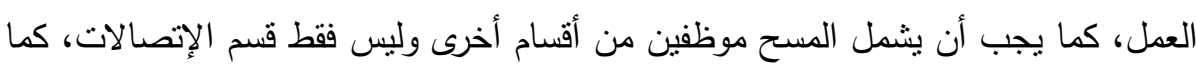

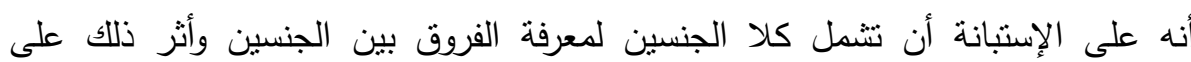

3- Natalia Petrova (2011) "Flexible work as an effective tool to increase organizational productivity"

تهدف الدراسة لاختبار افتراض ان العمل المرن يؤدى الى زيادة الانتاجية من وجهة نظر

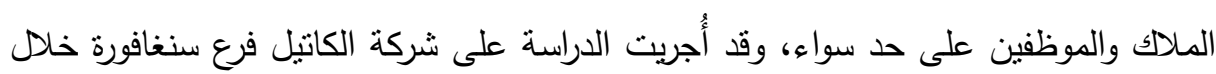

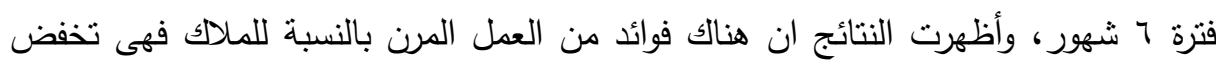
تكاليف شراء المبانى والمكاتب، وبالنسبة للموظفين فهى تؤدى الى تعاون فرق العمل بشكل أفضل، وتتيح اختيار أوقات العمل المناسبة، والمكان الأفضل لانجاز الأعمال ووسيلة

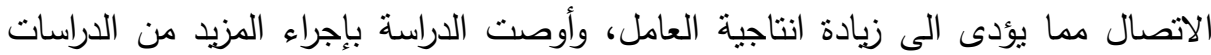


المستقبلية حول ثقافة المنظمات وتطوير استراتيجية عالمية تضعها الثركات العالمية فى مختلف الدول لتطبيق العمل المرن.

تعقيب على الدراسات السابقة: فى هذه الدراسة قام الباحثون باستعراض ( 6 ) دراسات سابقة

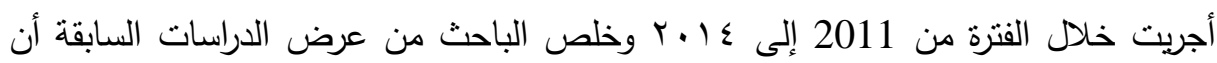

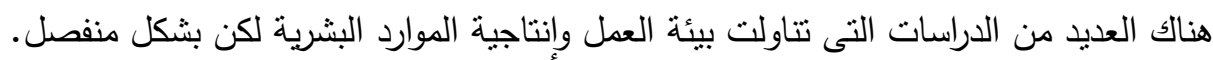

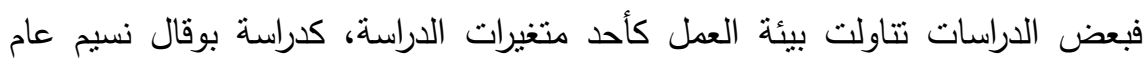

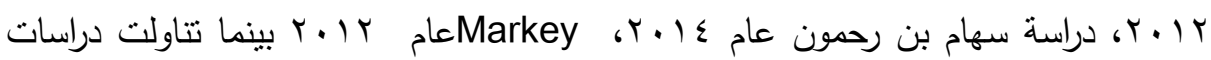

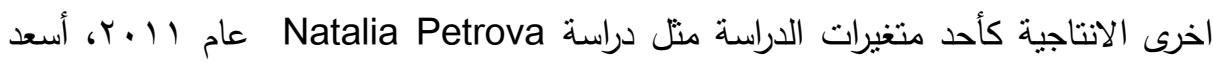

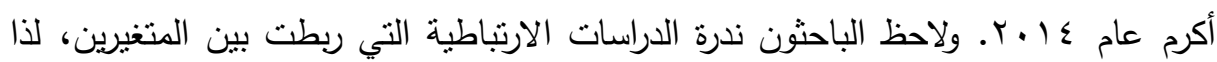
فالدراسة الحالية تختلف عن الدراسات السابقة فى انها ربطت بين جودة نظم العمل باعتبارها احد اهم مكونات بيئة العمل وبين إنتاجية الموارد البشرية ويتشابه معها فى ذلك دراسة Leblebici نظم العمل بينما دراسة Leblebici نتاول محاور اخرى من بيئة العمل وايضا مجتمع البحث

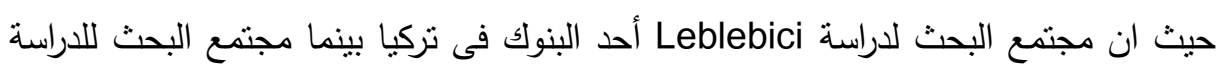

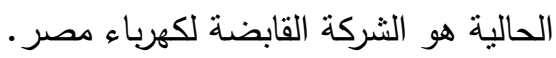

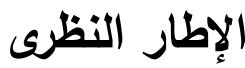

تلعب بيئة العمل دورا كبيرا فى تحقيق فاعلية الأداء بالمنظمات سواء كانت حكومية أو الور منظمات أعمال. وتشمل بيئة العمل عوامل كثيرة منها بيئة العمل الاجتماعية كحاجات الأفراد فى مجال العمل وجماعات العمل والإثراف، وبيئة العمل المادية كالتصميم المادى لمكان العمل من إضاءة وتهوية ودرجة حرارة ونظافة ونواحى جمالية.

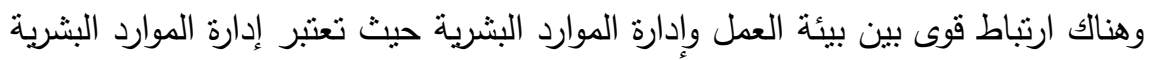

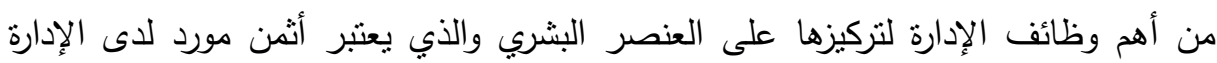

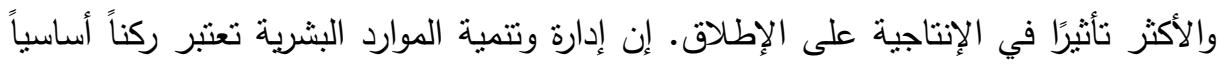

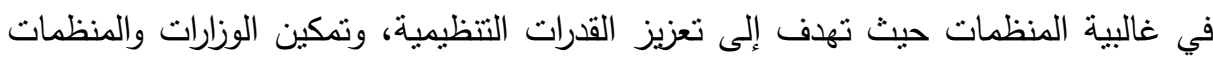

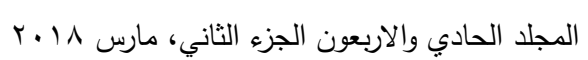


الحكومية والأهلية من استقطاب وتأهيل الكفاءات اللازمة والقادرة على مواكبة التحديات الحالية والمستقبلية. إن إدارة الموارد البشرية تعني باختصار الاستخدام الأمثل للعنصر البشري المتوفر والمُتوقَع على مدى كفاءة، وقدرات، وخبرات هذا العنصر البشري وحماسه للعمل تتوقف كفاءة المنظمة ونجاحها في الوصول إلى تحقيق أهدافها. لذلك أهتم علماء الإدارة بوضع المبادئ والأسس التي تساعد على الاستفادة القصوى من كل فرد في المنظمة من لهن خلال إدارة الموارد البشرية. هذه الأسس تندأ من التخطيط والاختيار والتدريب والحوافز والتقييم

( Marko Kesti,2012)

$$
\text { وكل ما لله صلة بالعنصر البشري. }
$$

أنواع بيئة العمل: بيئة العمل فى المنظمات تتقسم الى انواع مختلفة، وتحديد أنواعها يساعد على توضيح العلاقة القائمة بين كل بيئة وأخرى ويمكن تحديدها فى الأتى:

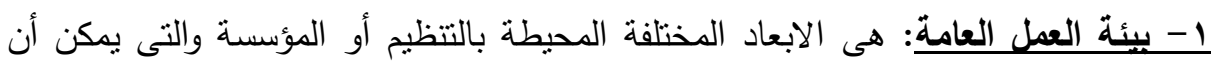

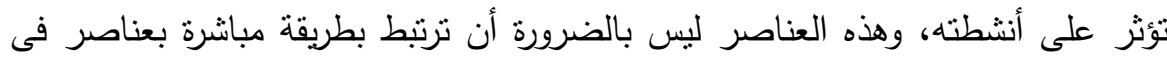

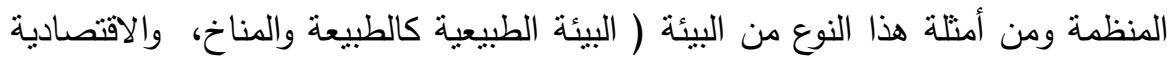
كالنظم الاقتصادية، والتكنولوجية كالمعرفة والثقدم والثقافية كالعادات والتقاليد ). اى ان البيئة العامة هى الاطار الذى تعمل فيه جميع التنظيمات والمؤسسات فهى نتشمل

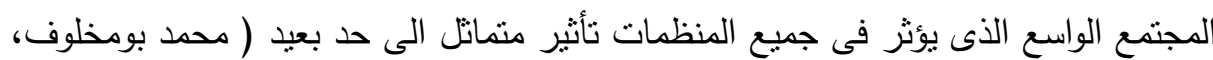

r - بيئة العمل الخاصة: هى البيئة التى تعيش فيها المنظمة بمفردها، ولا بشاركها أحد فى

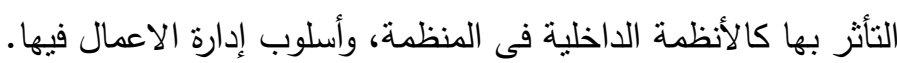
ويقصد ببيئة العمل الخاصة الابعاد الطبيعية والسياسية والاقتصادية والاجتماعية النى لهى تؤثر على منظمة بعينها، أو قطاع بذاته دون غيره . ب- بيئة العمل الخارحية: هى مجموعة الظروف والنظم والجماعات التى نتكل منظمة الأعمال وتعمل فى إطارها. ( على السلىى، لو99 1 )، فهى تمثل الإطار الخارجى الذى

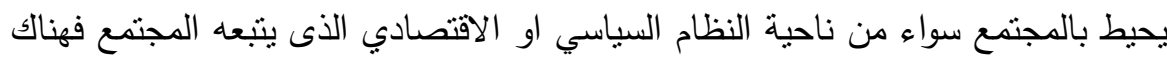

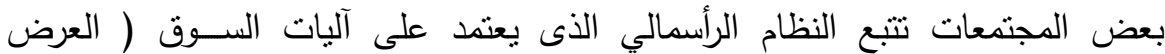


والطلب ) والمنافسة الحرة بين الثركات، وهناك بعض المجتمعات تتبع النظام الاثتراكي

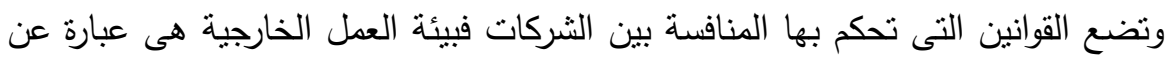
مختلف المؤثرات والمكونات والجوانب التى تحيط بالمنظمة وتتفاعل معها.

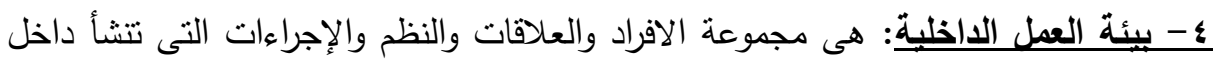
المنظمة ويتم من خلالها وبها تتفيذ الأعمال والوصول الى النتائج المطلوبة ـ ـههى الإطار

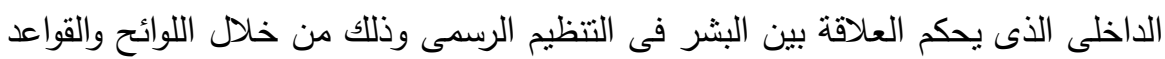

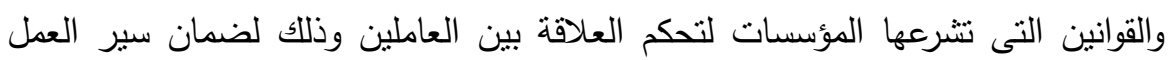
بصورة سليمة مع تحديد السلطات والاختصاصات وتطبيق نظام الثواب والعقاب، هذا

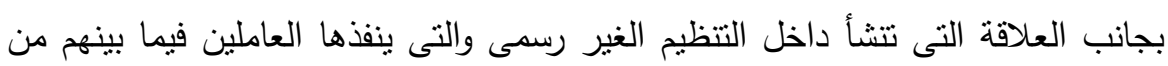
خلا إنشاء علاقات إنسانية واجتماعية. وهذا النوع من البيئة هو الذى سينصب عليه تركيز الباحثون لكونه المتغير المستقل لهذه الدراسة ولإبراز علاقته بالإنتاجية. نظم العمل واللوائح: تعتبر النظم واللوائح من بين أهم عناصر البيئة الداخلية، لأنها شرط

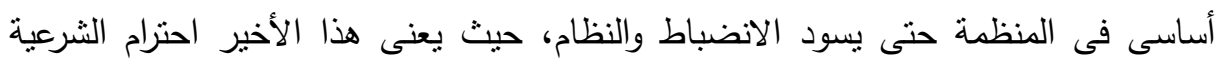

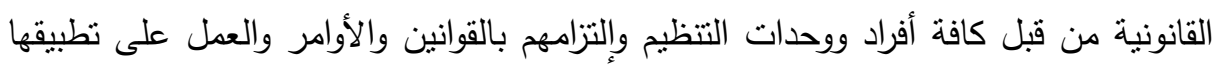

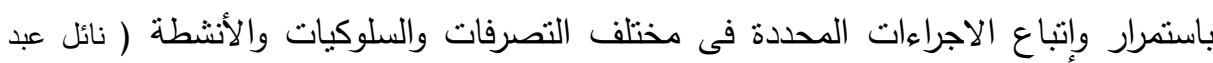

والأداة الاساسية لنطبيق النظم واللوائح هى الاجراءات فالإجراءات قد أكدت أهميتها

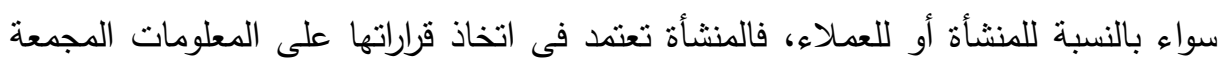
والإحصاءات والبيانات، وكلها تحتاج الى إجراءات للحصول عليها واستخدامها بكفاءة، وذللك باكتشاف أفضل طريقة لأداء العمل .

ويرى الباحثون ان الاجراءات هى مجموعة العمليات اللازمة لأداء العمل، مما يستوجب لاداء

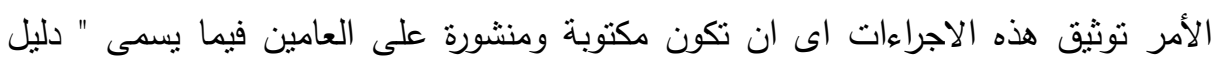
الاجراءات ". 
مفهوم الاجراءات:هى سلسلة من الخطوات المحددة مقدما والمرنبطة والمرنبة وفقا لتتابع زمنى لتتفيذ الأعمال التى ينسم أداءها بالروتينية ( محمود السيد، سوسن عبد الفتاح، بدون

$$
\text { ستة نشر). }
$$

ويمكن أن نستخلص من هذا التعريف بعض الحقائق التى من شأنها أن تؤدى الى تعقيد

$$
\text { الإجراءات وهى: ونى }
$$

1- طالما هى سلسلة فهذا يعنى ان هناك تسلسلا واجب الإتباع حسب نسق معين • وعدم وجود هذا التسلسل يؤدى الى التعقيد.

r- طالما هى مرتبطة فإن هذا يعنى ان هناك ترابطا معينا بين الإجراءات المتبعة، فكل إجراء يكمل الذى يسبقه ويليه... وغياب هذا الترابط يعنى وجود تعقيد.

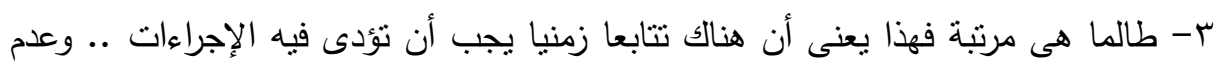
توافر هذا التتابع يعنى تعقد ما في الاجراءات.

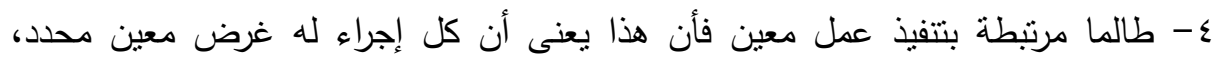

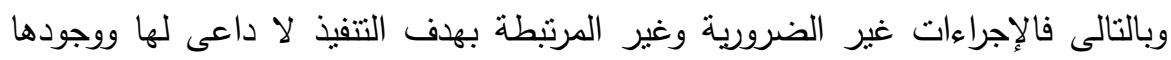
يساهم فى تعقيدها.

والبعض الأخر يرى ان الاجراءات هى الأعمال التقصيلية الرئيسية التى تسير على لثى

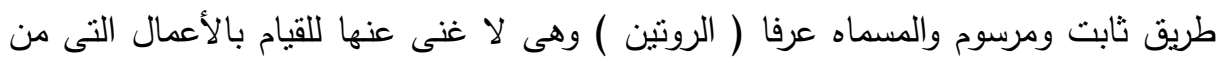

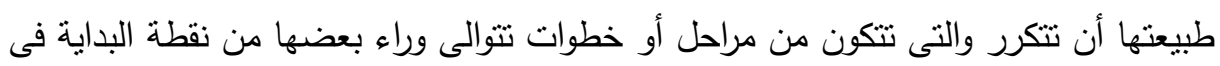

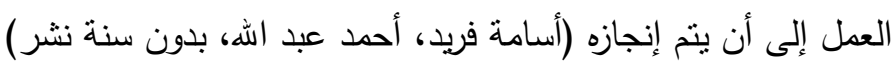

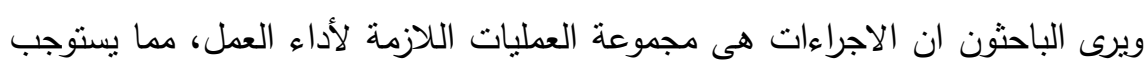

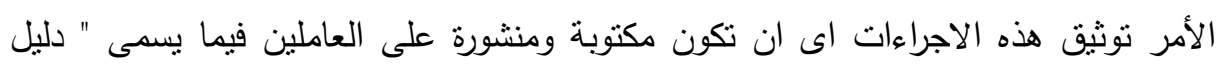

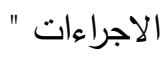


1 - تجنب التعطيل والاختتاقات : حيث يتم العمل بسهولة ويسر .

r- سرعة أفضل: فالانجاز السريع للعمل أمر ممكن طالما أن النظام قائم على طريقة العمل المستخدمة وليس على مجرد أهواء ونزوات فردية.

r- تحكم أفضل: لأن النظام يضمن سيطرة أفضل على العمل، ومن هنا يتم القضاء على كل أشكال التلاعب.

ع - الاقتصاد: يوفر النظام الجيد أيضا فى المصروفات والعمالة لأن طرق العمل قائمة على التحليل السليم وتتغير من وقت لأخر لملاحقة البيانات المتغيرة. ه- تجنب الاخطاء: بما أن الاجراءات والنظم قائمة على التحليل السليم فإن ذلك يؤدى إلى لى لئات تلاشى فرص الخطأ أو على الأقل تصل إلى إهلى ادنى حد من الخطأ. צ- تحرير الإدارة: فالإجراءات لا تقيد الإدارة بل على العكس تحررها وتسمح بتكريس نفسها للمهام الأخرى.

V- تدريب العاملين: فالإجراءات المكتبية تجعل تدريب العاملين يتم بطريقة أفضل، وبالتالى تتحسن كفاءة العاملين فى المكاتب.

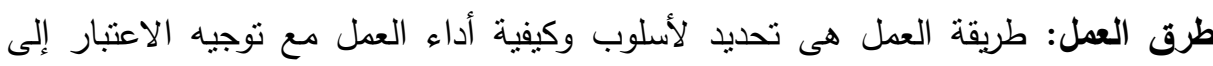
الهدف المنشود وإلى التسهيلات المتاحة وإلى التكاليف الكلية للوقت والمال والمجهود.

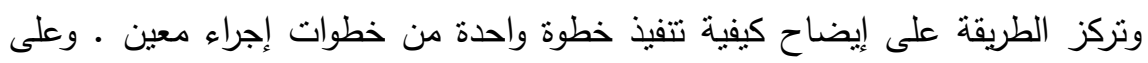
ذللك تتعلق الطريقة بجزء فقط من إجراء معين، ومن ثم فهى أكثر تحديدا فى مداها بالنسبة

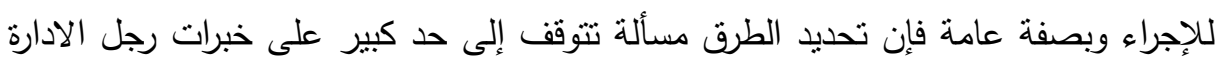

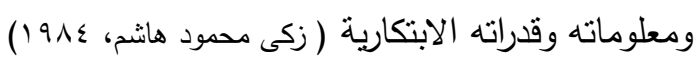
تبسيط الاجراءات: أول من أستخدم تعبير تبسيط الإجراءات فى تاريخ الإدارة الحديثة هو هونه

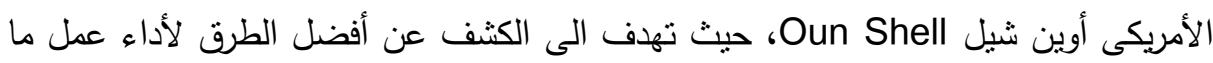
بأيسر الإجراءات وأكثرها إقتصادا حتى يمكن الاستفادة من الأيدى العاملة والمواد والالات

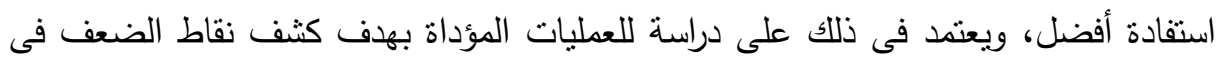

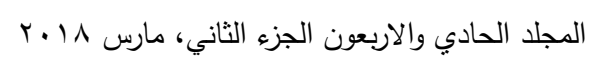


تسلسل كل عملية من العمليات أو الوقت الضائع أو الخطوات الزائدة . وتعرف تبسيط الاجراءات بأنها طريقة لتتفيذ العمليات بقصد الاستغناء عن الخطوات غير الضرورية لتحقيق

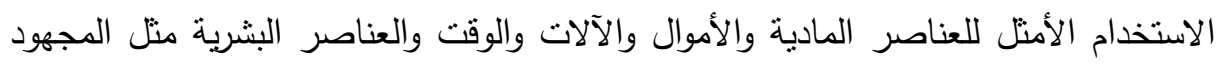
الذهنى والعصبى والعضلى.

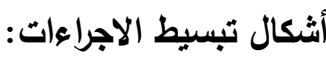

1- الإدماج: أى دمج أكثر من إجراء تبعا معا بعد التأكد من ضرورة كل من هذه الإجراءات

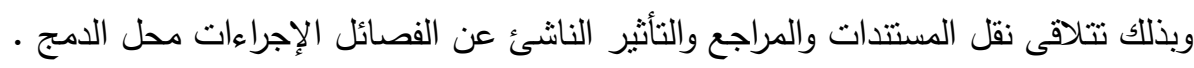

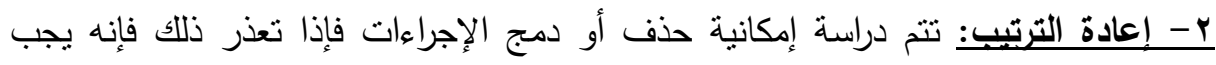

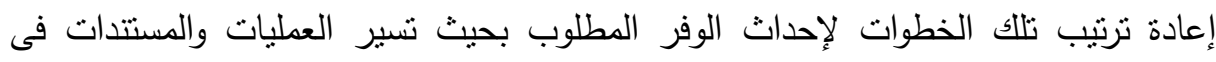
اتجاه واحدة توفيرا للجهد والوقت. ب- الحذف: وينطبق على الإجراءات غير ذلك ذات الضرورة بعد الدراسة التحليلية لها وبذلك ودير

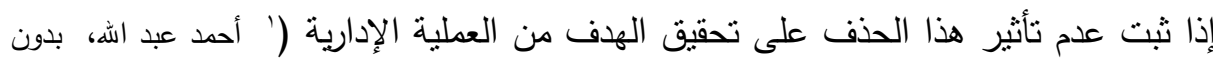
سنة نشر ) الإنتاجية: وتعتبر الإنتاجية من حيث كونها علاقة بين الدذخلات والمخرجات بصورها المختلفة مجرد فكرة نسبية تتوقف على شكل العلاقة الممثلة والظروف المحيطة والعوامل

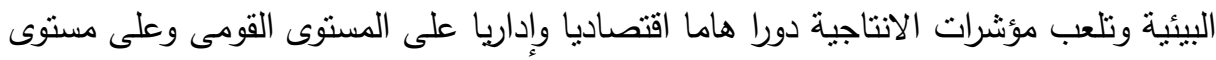

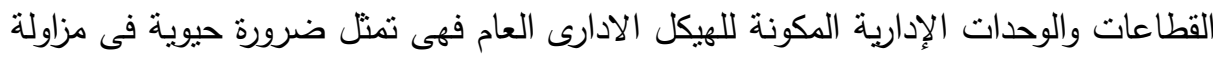
الأنشطة المختلفة. ولقد عرفت منظمة العمل الدولية الانتاجية بانها النسبة الحسابية بين مخرجات الثروة

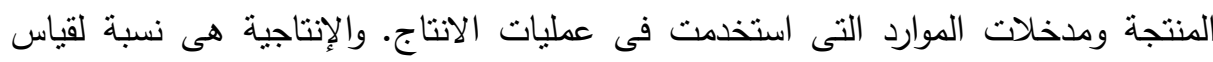
مدى نجاح المنظمة (أو الفرد أو الصناعة أو الدولة ) بتحويل موارد المدخلات (اليد العاملة الدئل

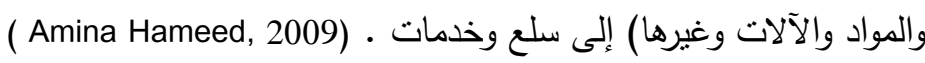


أهمية الإنتاجية: تعد الإنتاجية مؤشرا هاما يستدل من خلاله على درجة التطور والتقدم الذي

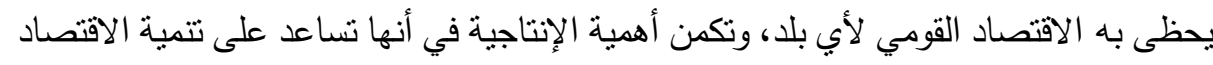

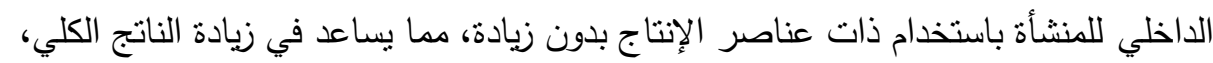

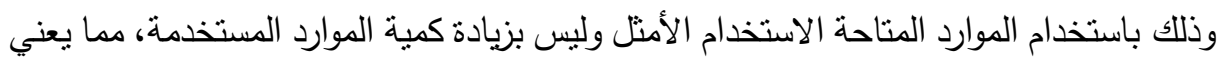
تقدم مستوى المعيشة على المستوى القومي، ومن ثم تعتبر الإنتاجية المصدر الأهم للتتمية

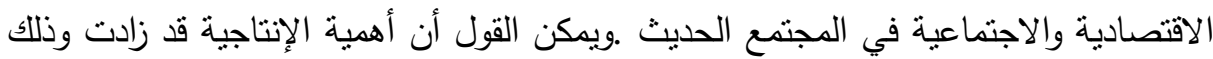
بسبب ندرة الموارد، ومن الضروري الاهتمام برفع معدلات الإنتاجية وتحسين استغلال الموارد

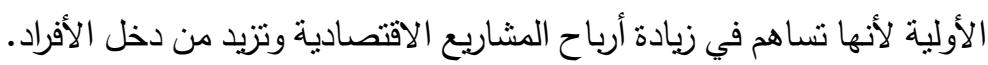

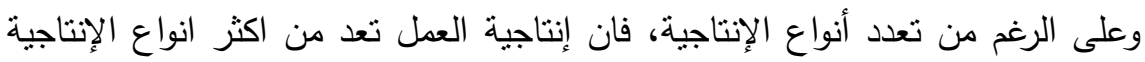

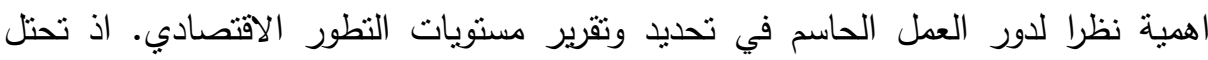

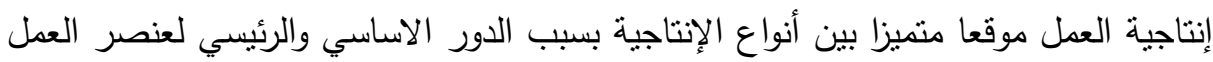

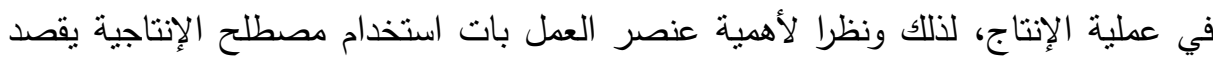

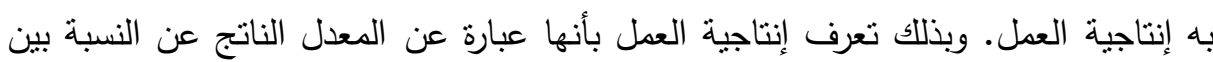
كمية الإنتاج وبين عدد المشتغلين، او عدد ساعات العمل.

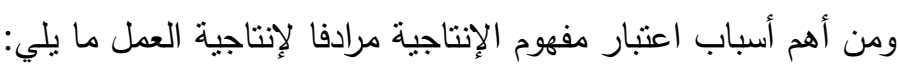

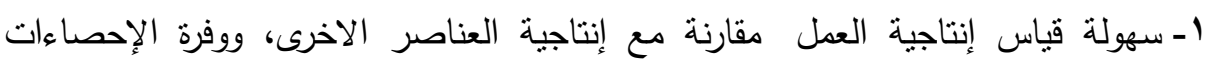

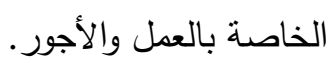

r- الدور الفعال الذي يؤديه عنصر العمل في العملية الإنتاجية كونه العنصر الرئيس الذي تتوقف عليه زيادة الإنتاجية. r- الدور الهام الذي يلعبه عنصر العمل في رفع مستوى معيشة الأفراد فارتفاع مستوى لئه

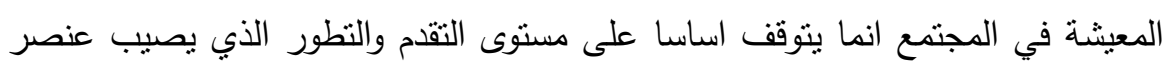

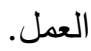




\section{السراسمة الميشانيه}

تمهيد: تم القيام بعمل دراسة ميدانية على ديوان عام الثركة القابضة ومجموعة من شركات الكهرباء التابعة وهى الثركة المصرية لنقل الكهرباء، شركة القاهرة لإتتاج الكهرباء، شركة دهرة جنوب القاهرة لتوزيع الكهرباء وذلك بهدف تقييم أثز جودة نظم العمل بالثركة القابضة لكهرباء مصر على انتاجية الموارد البشرية. أسلوب إجراء الدراسة الميدانيه: تم الاعتماد فى هذه الدراسة على استمارة الاستقصاء من إنى

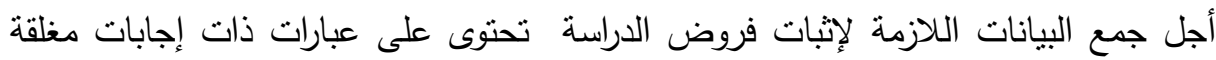

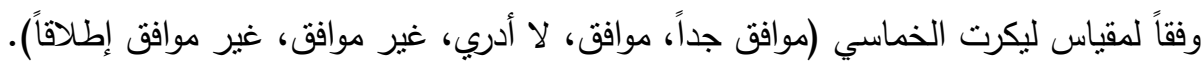

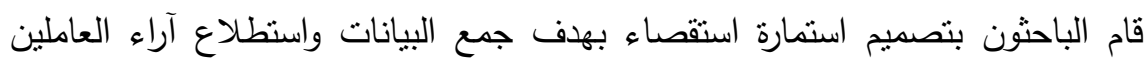
بالثركة القابضه لكهرباء مصر وقد قام الباحثون بتوزيع . .7 استمارة على هولاء الموظفين

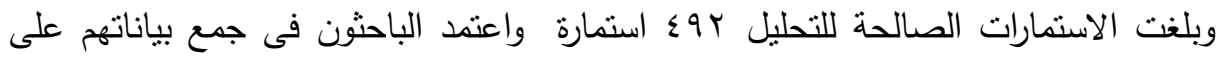

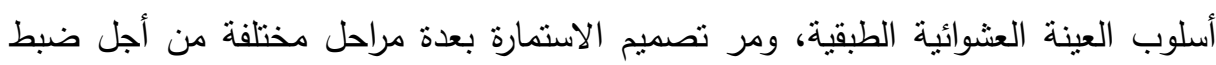
عملية إعدادها، وتمثلت تلك المراحل فى الآتى: - تم تحديد بيانات الاستمارة بناء على أهداف الدراسة وتنساؤلاتها وفرضيتها. - قام الباحثون باستخدام طريقة المقابلة الثخصية مع الأشخاص المستقصى منهم لجمع الثعان

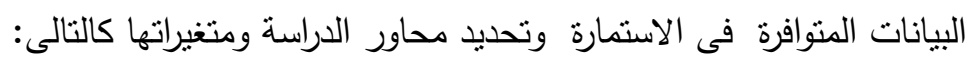
المحور الاول: جودة نظم العمل ويعبر عن الوسط الحسابى للاجابات على عبارات هذا لاتهات المحور المتغير Q وعدد العبارات لهذا المحور • (1 عبارات. الدحور الثنانى: إنتاجية الموارد البشرية ويعبر عن الوسط الحسابى للاجابات على عبارات هذا المحور المتغير Y وعدد العبارات لهذا المحور • ل عبارات. 
الجدول التالى يعرض محاور الدراسة ونوع المتغير وعدد عبارات كل متغير ورمز كل متغير جدول رقم(1): محاور الدراسه ومتغيراتها ونوع المتغير وعدد العبارات ورموز العبارات

\begin{tabular}{|c|c|c|c|c|c|}
\hline المتغير & رموز العبارات & عدد العبارات & نوع المتغير & المحور & الترتيب \\
\hline$Q$ & $X_{1}$ to $X_{10}$ & 1. & مستقل & جودة نظ العمل & الاول \\
\hline$Y$ & $X_{11}$ to $X_{20}$ & 1. & تابع & إنتاجية الموارد البشرية & الثاني \\
\hline
\end{tabular}

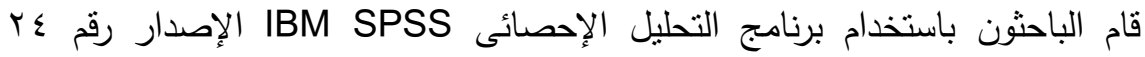
المستخدم فى البحوث الإنسانية والإجتماعية عند تحليل بيانات استمارات الإستقصاء ـ وتم عمل التحليل الإحصائى على النحو التالى: أولاً: اختبار الفا كرونباخ للتحقق من ثبات وموثوقية العبارات الخاصه بكل محور محور من محاور

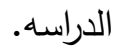
جدول رقم(ץ): قيمة اختبار الفا كرونباخ وعدد العبارات لكل محور

\begin{tabular}{|c|c|c|c|}
\hline عدد العبارات & معامل الفا كرومباخ & المحور & المتغير \\
\hline 1. & $\wedge 91$, & جودة نظم العمل & $\bar{Q} \mathbf{Q}$ \\
\hline 1. & $\wedge \wedge \varepsilon$, & إنتاجية الموارد البشرية & $\mathbf{Y}$ \\
\hline
\end{tabular}

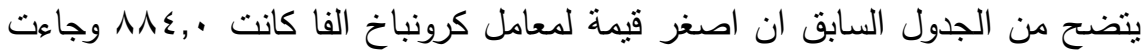
لمتغير "إنتاجية الموارد البشرية"، وطبقاً لمستويات معامل كرونباخ الفا فأن جميع متغيرات الدراسه لها اتساق داخلى جيد، وهذا يعنى امكانية الوثوق فى هذه البيانات فى التحليل

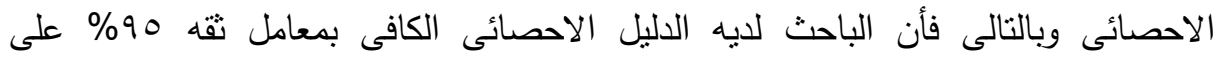
مصداقية البيانات التى تم جمعها، ولهذا سوف يتم الاعتماد على هذه البيانات فى التحليل الاحصائى واختبارات الفروض.

ثانيا : اختبارات ومقاييس الإحصاءات المارت المعملية :

للتعرف على اتجاه آراء افراد العينة فى الأسئلة التى وجهت اليهح من خلال استمارة

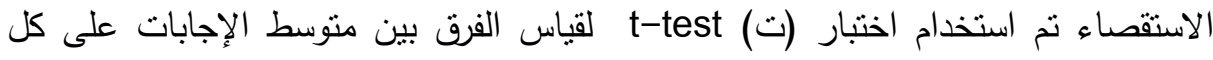

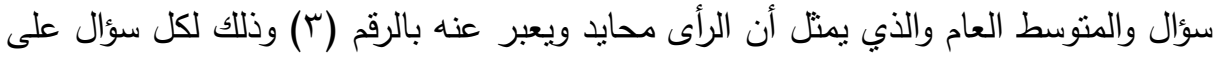

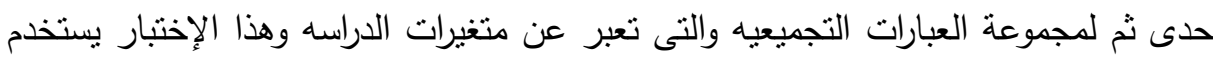
لقياس الفرق بين منوسط الإجابة والمتوسط العام ويحدد ما إذا كان هذا الفرق جوهرى أم انه

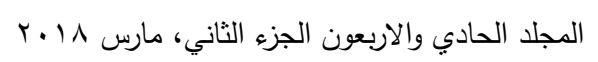


يرجع الى عوامل الصدفة، وفى حالة أن القيم الإحتمالية المحسوبة أصغر من ه\% وهو

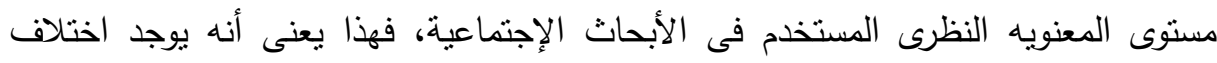

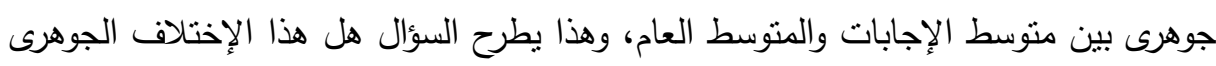
موجب ام سالب أو بأسلوب آخر هل هو اكبر من المتوسط العام ام اصغر من المتوسط العام

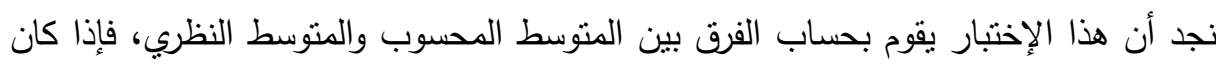
الفرق موجب فهذا يعنى أن متوسط الإجابات على هذه الأسئلة أكبر من المتوسط أى ألى أن

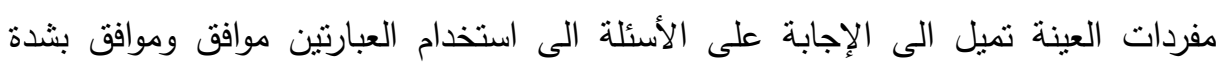
وهاتين العبارتين لهما وزن نسبى ع، 0 على الترتيب وهذا يعنى أن مفردات العينة تؤيد هذه الإنه الأسباب، أما إذا كان الفرق سالب فهذا يعنى أن مفردات العينة تميل الى العين الإجابة على الأسئلة

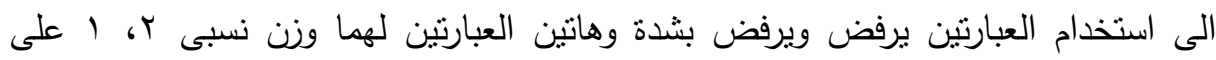
التزتيب وهذا يعنى ان مفردات العينه ترفض هذه الاسباب.

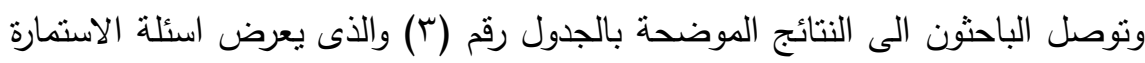

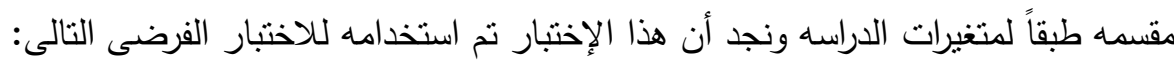

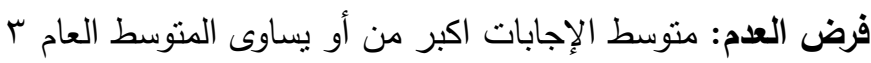

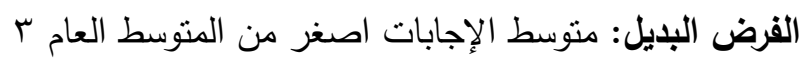


أحمد مندور وآخرون

جدول رقم(r): استخدام اختبار (ت) لأسئلة استمارة الاستقصاء

\begin{tabular}{|c|c|c|c|c|c|}
\hline 12 & قبر & ئبة انسريك & 4 & 先 & הدمد \\
\hline 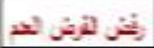 &,$+ *+$ & $-\infty, 37$ & 空 & $x_{1}$ & \multirow{10}{*}{$\frac{E}{E}$} \\
\hline 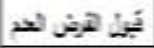 & 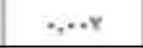 & $\mathrm{r}, \mathrm{rrT}$ & 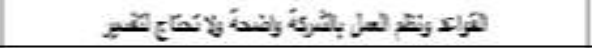 & $x_{T}$ & \\
\hline إن & $\cdot, .2 t$ & $-1,4,27$ & 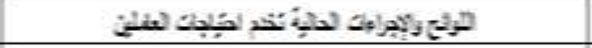 & $x+$ & \\
\hline تُبل عزض لحد & $*, \cdots 1$ & $r, 4: 2-$ & $4+4 x^{3}+43$ & $x_{i}$ & \\
\hline 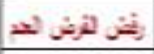 &,$+ 2 \% a$ &., $2 \mathrm{rt}-$ & 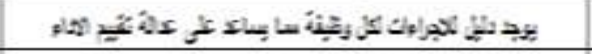 & $x=$ & \\
\hline 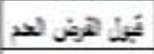 & $\ldots, \cdots r$ & $-r, v+r$ & 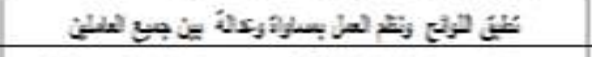 & $x:$ & \\
\hline 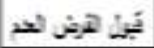 &,+ 12 & $\mathrm{t}, \mathrm{str}$ & 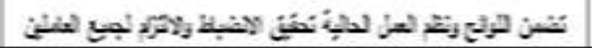 & $x_{v}$ & \\
\hline 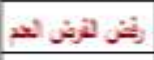 &,$+ 4=$ &,$+ \cdot \pm \cdot-$ & 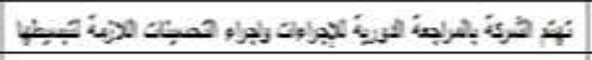 & $x_{i}$ & \\
\hline 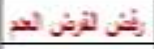 & 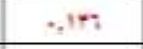 & $-1, \pm \pm r$ & 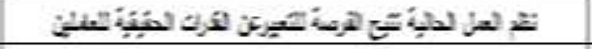 & $x ;$ & \\
\hline 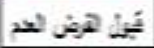 & $* \cdots$ & $0,1 \ldots$ & 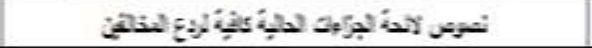 & $x_{1}$. & \\
\hline 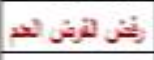 & $+\pi$ & $-\infty, 451$ & 然 & $\mathbf{x} \div$ & \\
\hline 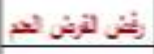 & $+,+2)$ & , $5+7-$ & 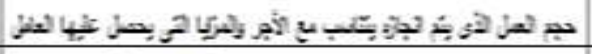 & $x_{1 \pi}$ & \\
\hline 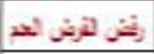 &,$+ A+:$ & $-, r_{1}:-$ & 管 & $x:=$ & \\
\hline 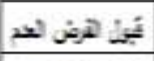 & $+\cdots$ & $2,1 \pi v$ & 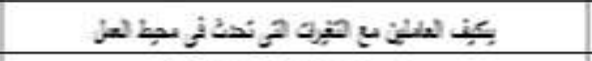 & $x_{1:}$ & \\
\hline 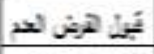 & $\ldots, \cdots$ & $t, 52$ & 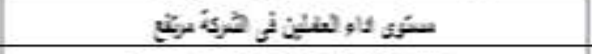 & $\mathbf{X}_{\alpha}$ & \\
\hline 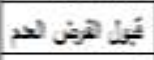 & $\therefore, \cdots$ & $t, y=2$ & 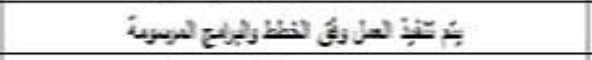 & $x_{-1}$ & \\
\hline 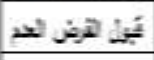 & $*, \cdots$ & $8,+-5$ & 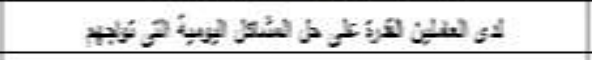 & $x$ & \\
\hline 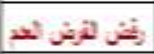 &, $+ \pm \pm *$ & $\cdot, \mathrm{mrt}$ & 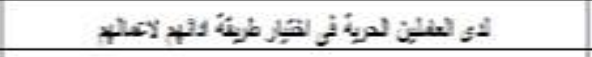 & $x$. & \\
\hline 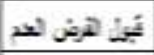 & $\cdot, \cdots$ & t, $1+4$ & 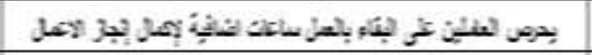 & $x: a^{2}$ & \\
\hline 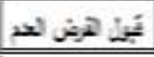 &.,$\cdots$ & $\mathrm{sin}$ & 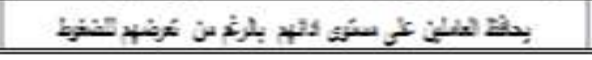 & $x$ & \\
\hline
\end{tabular}

من الجدول السابق نجد أنه تم قبول الفرض العدم للعبارات المظلله وعددها 11 عباره

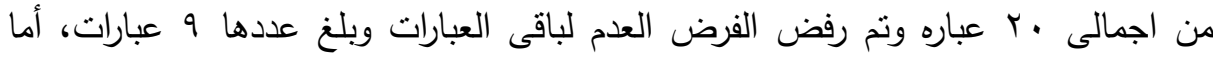

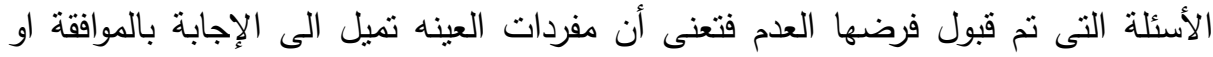

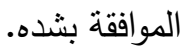

أما باقى الأسئلة فإن رفض الفرض العدم لها يؤكد أن الإجابات تميل الى الرفض او

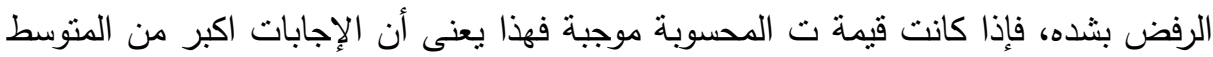

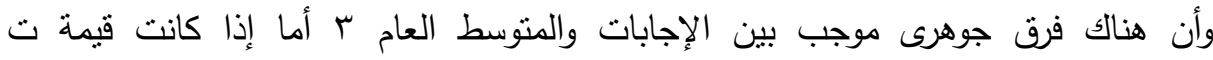


المحسوبة سالبة فهذا يعنى أن الإجابات كانت اقل من المتوسط وأن هنالك فرق جوهرى سالب

$$
\text { ويتض الإجابات والمتوسط العام س. }
$$

- محور "جودة نظم العمل" يحتوى على 0 عبارات تم رفض الفرض العدم فيها. - محور "إنتاجية الموارد البشرية" يحتوى على ع عبارات تم رفض الفرض العدم فيها.

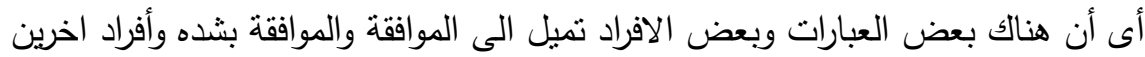
يميلون الى الرفض أو الرفض بشده، وللفصل بين هذين الرائيين تمكن الباحثون من تعميم هذه اله

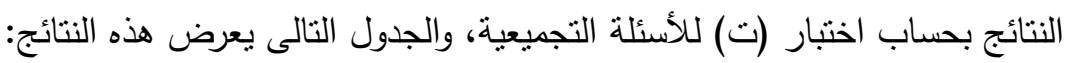

\begin{tabular}{|c|c|c|c|}
\hline القيمه الاحتماليه & قيمة ت المحسويه & المحور & المتغير \\
\hline 0.032 & 4.212 & جودة نظم العمل & $Q$ \\
\hline 0.000 & 4.232 & إنتاجية الموارد البشرية & $\bar{Y}$ \\
\hline
\end{tabular}
جدول رقم(؛ ): اختبار (ت) لمتغيرات الدراسه (للعبارات التجميعيه)

من الجدول السابق رقم (ع) يتضح انه يمكن قبول الفرض العدم باحتمال 90\% لمحاور الدراسة، وهذه النتائج تؤكد ان عبارات الاستمارة التى نم رفض الفرض العدم لها يمكن التجاوز عنها فى عبارات محاور الدراسة وهذا يؤكد ان الافراد المُستقصى منهم يميلون الى الموافقة أو الموافقة بشده على عبارات الاستمارة. وبحساب الوسط الحسابى لمتغيرات الدراسة لتحديد مستوى منوسط الاجابات على مقياس ليكرت الخماسى فقد توصل الباحث الى النتائج الناليه:

\begin{tabular}{|c|c|c|c|c|}
\hline طبيعة الاجابه & لمقياس ليكرت الابهُ طبقحاً & الوسط الحسابى & المحور & المتغير \\
\hline موافق & 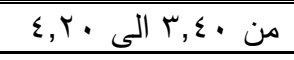 & $r, v \cdot \Lambda$ & جودة نظم العمل & Q \\
\hline موافق بشده & من الr, الى 0 & $\varepsilon, 0 \leqslant V$ & إنتاجية الموارد البشرية & $\mathrm{Y}$ \\
\hline
\end{tabular}
جدول رقم(•): الوسط الحسابى لمتغيرات محاور الدراسه

من الجدول السابق رقم (0) يتضح أن اراء مفردات عينة البحث يميلون الى الموافقة أو لون الموافقة بشده، وبالتالى فيمكن احصائيا اهمال العبارات التى تم رفض الفرض العدم فيها. 
اختبار فرض الاراسة: لاختبار الفرض، قام الباحث بتحليل علاقة الارتباط بين متغيرات الدراسه (جودة نظم العمل Q، إنتاجية الموارد البشرية Y ) وتوصل الباحثنون الى النتائج التاليه: جدول رقم(7): مصفوفة الارتباط بين متغيرى الدراسه

\begin{tabular}{|c|c|c|c|c|}
\hline Q7 & Q2 & \multirow[b]{2}{*}{ البيان } & \multirow[b]{2}{*}{ المحور } & \multirow[b]{2}{*}{ المتغير } \\
\hline إنتاجية الموارد & جودة نظم العمل & & & \\
\hline & 1 & معامل ارتباط بيرسون & \multirow{2}{*}{ جودة نظم } & \multirow{2}{*}{ Q } \\
\hline & & القيمه الاحتماليه & & \\
\hline 1 & 0.632 & معامل ارتباط بيرسون & \multirow{2}{*}{ إنتاجية الموارد } & \multirow{2}{*}{ Y } \\
\hline & 0.000 & القيمه الاحتماليه & & \\
\hline
\end{tabular}

من الجدول السابق رقم(ך) يمكن استتناج ما يلى: هناك علاقة معنوية بين جودة نظم العمل (Q2) المتغيرين 0.632 وهذا يدل على وجود علاقة ارتباط طرديه ومتوسطة القوه بين هذين المتغيرين وبأختبار معنوية معامل الارتباط اتضح ان القيمه الاحتماليه لاختبار t اصغر من 0\% (مستوى المعنويه) وهذا يدل على ان علاقة الارتباط جوهريه بين جودة نظم العمل (Q2) إنتاجية الموارد البشرية (Y) (Y) )

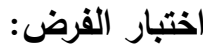
الفرض العدم: توجد علاقة جوهرية بين جودة نظم العمل وإنتاجية الموارد البشرية بالثركة

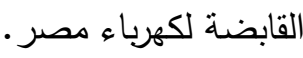
الفرض البديل: لا نوجد علاقة جوهرية بين جودة نظم العمل وإنتاجية الموارد البشرية بالثركة

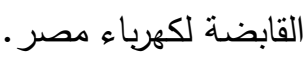
القرار: اعتماداً على تحليل الارتباط يمكن قبول الفرض العدم باحتمال 90\% \% نتائج اختبار الفرض: ينص الفرض على انه "توجد علاقة جوهرية بين جودة نظم العمل

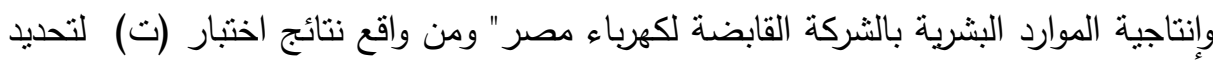

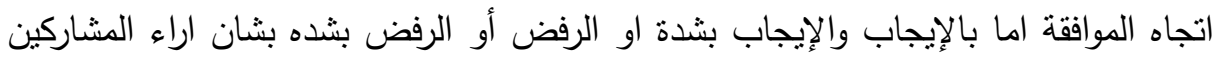

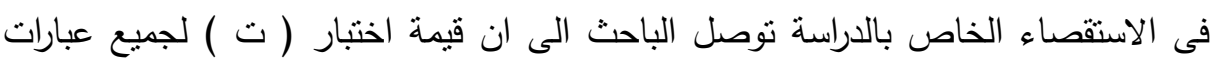

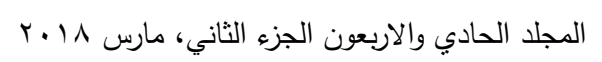


متغيرات الدراسه الخاصه بجودة نظم العمل موجبة وذات دلالة احصائية، كما ان قيمة الاختبار لمتوسط جميع العبارات انتاجية الموارد البشريه ايضاً موجبة وذات دلالة العيه الحصائية

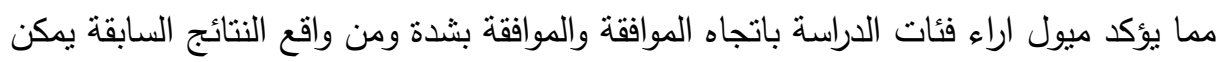
قبول الفرض العدم ومن ثم القول بان جودة نظم العمل تؤثز معنوياً على انتاجية الموارد البشرية.

\section{اللنمانكم}

أولاً: نتائج خاصة باختبار فرض الاراسة: نوجد علاقة جوهرية بين جودة نظم العمل وإنتاجية الموارد البشرية بالثركة القابضة لكهرباء مصر . ثانياً: نتائج خاصة باتجاهات وأراء مجتمع البحث نحو متغيرات الدراسة: اظهر

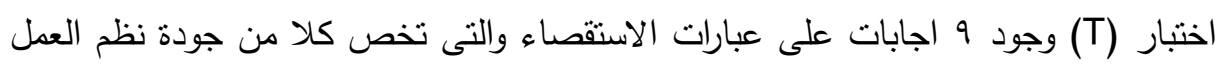

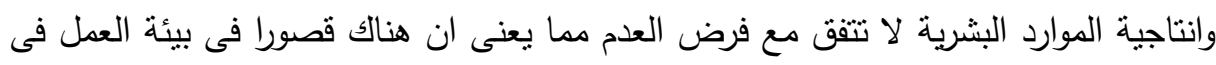

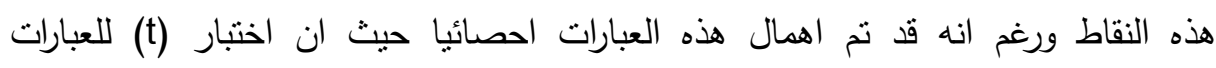

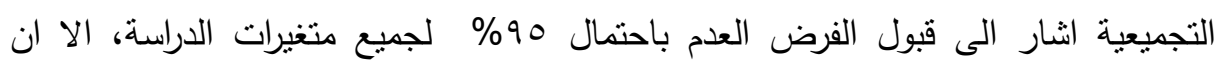

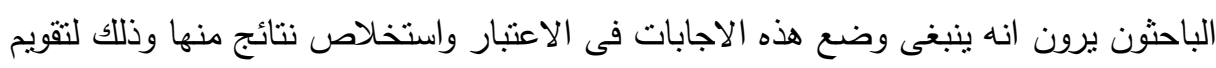

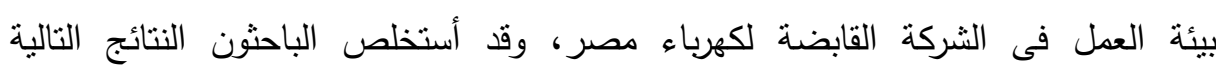
والخاصة بكل متغير كالآتي:

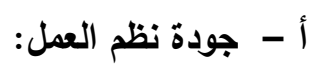

1 - لا يتم الاطلاع على اللوائح ونظم العمل عند بداية شغل الوظيفة.

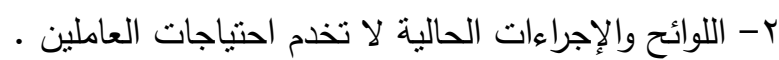
r- الا يوجد دليل للاجراءات لكل وظيفة مما يساعد على عدالة تقييم الاداء. ع- لا تهتم الثركة بالمراجعة الدورية للإجراءات واجراء التحسينات اللازمة لتبسيطها. ه- نظم العمل الحالية لا تتيح الفرصة للتعبير عن القدرات الحقيقية للعاملين . 


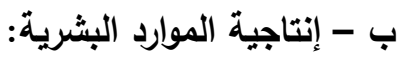

1- لايتم الاستفادة من كل ساعات العمل المقررة. r- حجم العمل الذى يتم انجازه لا يتتاسب مع الأجر والمزايا التى يحصل عليها العامل. ب- با بتم استغلال جميع الامكانيات المتاحة في الشركة.

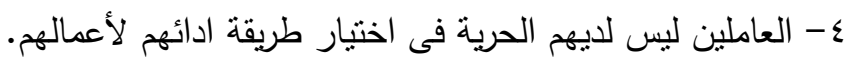
وهذه النتائج تتفق مع نتائج الدراسات السابقة التى نم استعراضها بوجود علاقة جوهرية بين جودة نظم العمل وإنتاجية الموارد البشرية باعتبار ان جودة نظم العمل هى احد محاور

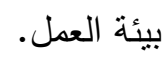

\section{الموكياته}

ا - ضرورة اطلاع العامل الجديد على اللوائح المنظمة للعمل وكذلك مدونة السلوك الوظيفى عند استلامه العمل وذللك حتى يكون على دراية كاملة بحقوقه وواجباته قبل ممارسة مهام وظيفته مما يقلل من اخطاءه. r- تعديل اللوائح المنظمة للعمل وتوحيدها بما يتلائم مع الظروف الحالية التى تمر بها

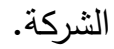

$$
\text { r- مراجعة الاجراءات الحالية بالثركة وتبسيطها لتقليل الوقت اللازم لأداء المهام. }
$$
ع - اعداد دليل اجراءات لكل وظيفة مما يسهل الرجوع اليه عند الحاجة ويعتبر وسبلة لفهم اجراءات تتفيذ المهام بالنسبة للعامل الحديث العهد بالوظيفة. 0- اعطاء الفرصة للمديرين للتصرف بمرونة وعدم التقبد بالتتفيذ الحرفى للقواعد والتعليمات . 7- تدريب المديرين على استخدام مختلف الانماط القيادية تبعا للمواقف التى يواجهونها

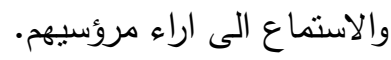

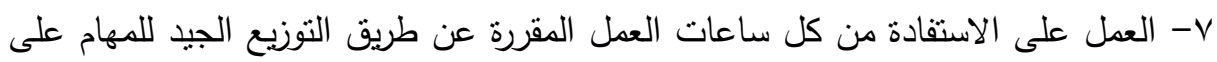
العاملين وتدريب العاملين على مفاهيم إدارة الوقت. 
1- اعطاء العاملين الحرية فى طريقة ادائهم لوظيفتهم مادامت هذه الطرق تتفق مع السياسة العامة للشركة ولا تخالف القواعد المتبعة وتحقق الاهداف الموضوعة من قبل الادارة.

\section{المراني}

أحمد عبد اله: " نطوير المنظمات "، مركز التعليم المفتوح، كلية التجارة، جامعة عين شمس، بلك بدون سنة نشر

أسامة فريد، أحمد عبد الله: " نطوير المنظمات "، مركز التعليم المفتوح، كلية التجارة، جامعة عين شمس، بدون سنة نشر

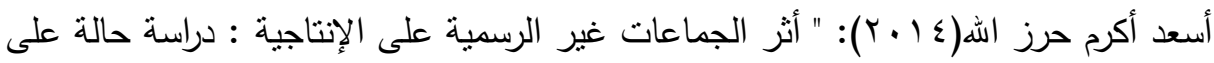

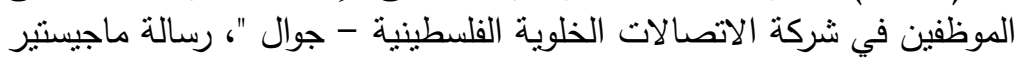

$$
\text { كلية التجارة، جامعة غزة، فلسطين }
$$

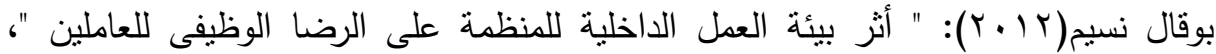

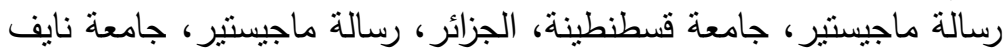

العربية للعوم الأمنية، المملكة العربية السعودية فينة التمائر،

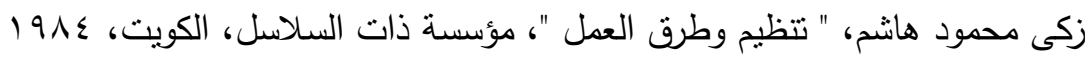

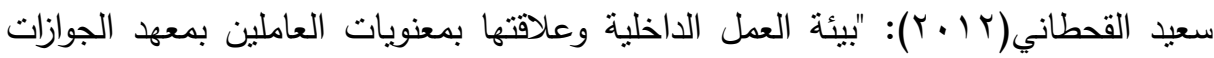
بالرياض"، رسالة ماجيستير، جامعة نايف العيلة العربية للعوم الأمنية، المملكة

$$
\text { العربية السعودية }
$$

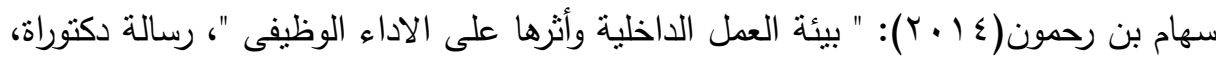
جامعة محمد خيضر - بسكرة، الجزائر

على السلمى(997 (19): " إدارة الموارد البشرية "، دار غريب للطباعة والنشر ، القاهرة محدد بومخلوف( ( . . ب): " التتظيم الصناعى والبيئة "، الجزائر ، دار الأمة

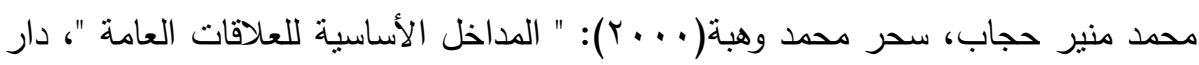

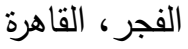

محمود السيد، سوسن عبد الفتاح ،" تشخيص المشكلات الإدارية والتنظيمية "، مركز التعليم

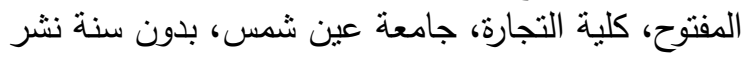




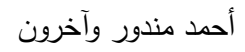

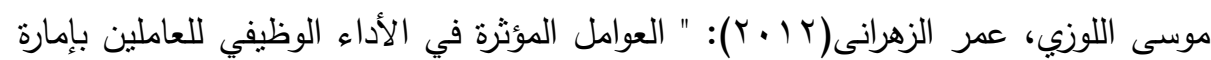

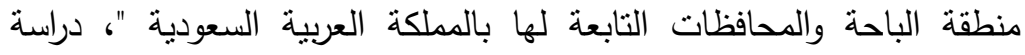

تحليلية، مجلة دراسات العلوم الإدارية

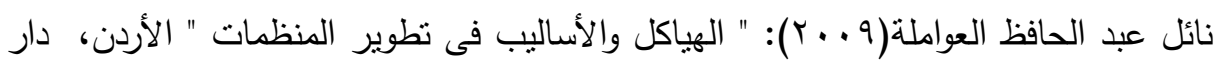
زهران

Amina Hameed," Impact of Office Design on Employees' Productivity", Journal of public affairs , Administration and Management, Volume 3, Issue 1, 2009

Natalia Petrova, “ Flexible work as an effective tool to increase organizational productivity”, 20.

Marko Kesti, "Organization human resources devlopment connection to business performance" , Procedia Economics and Finance, vol 2, 2012.

Mas'udah Asmui and others, "The Importance of Work Environment - Facilities, International Journal of Learning \& Development, vol 2, issue 1, 2012..

Markey, et al. , " The Impact of The Quality of The Work Environment on Employees' Intention to Quit ”, 2012.

Leblebici:," Impact of Workplace Quality on Employee's Productivity:

Case Study of a Bank in Turkey", 2012.

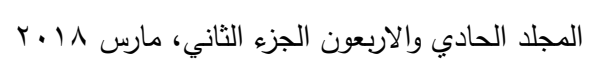




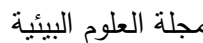

معهذ الدراسات والبحوث البيئية - جامعة عين شمس البئ

\title{
THE IMPACT OF THE QUALITY OF THE WORK \\ SYSTEMS OF THE EGYPTIAN ELECTRICITY \\ HOLDING COMPANY ON THE PRODUCTIVITY OF \\ HUMAN RESOURCES
}

\begin{abstract}
Mandour, A. ${ }^{(1)}$; Salam, S. ${ }^{(1)}$ and Abdel Aziz, H. A. ${ }^{(2)}$
1) Faculty of Commerce, Ain Shams University (2 Egyptian Electricity Holding Company
\end{abstract}

\begin{abstract}
The focus on human resources has been increasing in contemporary administrations, where management has found the important role that these resources play in helping to achieve departmental objectives.

The work environment is one of the important aspects of the success of modern business institutions and institutions, which are currently receiving increasing international attention, since the satisfaction of the employees of the organization with the work environment is reflected in their efficiency and performance, and thus the success of the institution.

The research aims to evaluate the impact of the quality of the work systems of EEHC on the productivity of human resources. The researchers compared the productivity of the worker with the holding company and three regional electricity companies to ensure that there is a decrease in the productivity of the employee in the holding company. The research examined the relationship between the quality of work systems and the productivity of human resources. In order to test the imposition of the study, the descriptive and analytical approach was adopted. A number of scientific papers were prepared in the same field of study and a collection of books, references and annual reports of the companies in question. The researchers used a number of key tools such as personal interview and survey, where a field study was conducted on 404

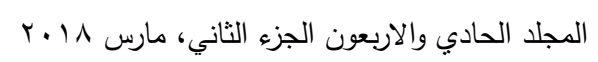




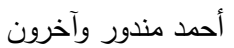

the General Office of the Holding Company and a group of electricity companies, The Egyptian Electricity Transmission Company, the Cairo Electricity Production Company, the South Cairo Electricity Distribution Company to prove the hypothesis of the research. The researchers designed a survey form for the purpose of collecting data and surveying the views of a sample of the employees of these companies. Groomed valid forms of analysis of 492 form, the researchers adopted in collecting data on the stratified random sampling method. The study confirmed that there is a fundamental relationship between the quality of the work systems and the productivity of human resources in addition to other results showed by the statistical analysis of the survey that was distributed. The study recommended that the new worker should be informed of the work regulations as well as the code of conduct when he receives the work so that he is fully aware In accordance with the current conditions of the company, as well as reviewing the current procedures of the company and simplify them to reduce the time required to perform tasks and prepare a manual of procedures for each job Which is easy to refer to when needed and is a means of understanding the procedures for the implementation of tasks for the newly employed worker. 